\title{
Increasing knowledge and changing views in cardiac resynchronization therapy
}

\author{
Laszlo Buga $\cdot$ John GF Cleland
}

Published online: 20 September 2011

(C) Springer Science+Business Media, LLC 2011

The introduction of cardiac resynchronization therapy (CRT) has changed the modern treatment of heart failure [1-4] and become a fruitful new area of research, especially imaging research $[5,6]$ and the development of "smarter" pacemaker technology [7-9].

One of the most important recent changes in perspective is the recognition that CRT may be an effective treatment for patients with substantial ventricular dysfunction whether or not their symptoms are severe. Several subanalyses of the first RCT's hinted that CRT was effective even in patients with mild symptoms [10-12]. Now, we have convincing evidence based on the REVERSE [13, 14], MADIT-CRT trials [15], and most recently the RAFT trial [16]. These trials show not only that CRT can retard or reverse the development of symptoms but also modify the progression of the underlying cardiac disease [14]. Indeed, implantation of devices in patients with substantial left ventricular dysfunction but only mild symptoms may have a greater overall impact on patients' well-being and longevity [1, 2, 12-14]. Recently updated European and North American guidelines have widened the recommendation for CRT to patients with mild symptoms [17, 18]. However, the story is not yet complete. Registries suggest that about half of patients who die from progressive heart failure within 2 years after ICD implantation have a QRS duration of less than $120 \mathrm{~ms}$ at the time of implant [19]. Observational studies also reported that younger patients with less

\footnotetext{
L. Buga $(\bowtie) \cdot$ J. G. Cleland

Academic Cardiology, University of Hull, Castle Hill Hospital, MRTDS Building, Castle Road, Cottingham,

Kingston-upon-Hull HU16 5JQ, UK

e-mail: laszlo.buga@hey.nhs.uk

J. G. Cleland

e-mail: J.G.Cleland@hull.ac.uk
}

advanced heart failure (including less enlarged ventricular volumes and narrower QRS) may gain more benefit from CRT in the long run than more advanced cases [20-26]. These findings may shift attention onto the importance of the timing of CRT implantation in early-stage heart failure.

Less progress has been made regarding the prediction of which patients benefit and by how much and how to optimize CRT. The use of the terms "responder" and "non-responder" oversimplifies the situation and is unhelpful as a concept or in clinical practice and in any case what is usually reported is outcome rather than response. The concept of response is heavily confused with the concept of outcome but they are very different things [27]. The best outcomes with CRT occur in patients who did not need CRT and had no response-in other words patients who were too well ever to benefit! Patients who are very sick may respond well to CRT with improved symptoms and survival but, nonetheless, are at higher risk of a poor outcome over the subsequent year [27]. Outcomes to CRT are variable amongst individuals, spanning a spectrum from so-called super-responders to patients who appear to have no benefit in terms of cardiac function, symptoms or survival. Outcome is highly dependent on the substrate being treated (i.e. the patients and their heart), and only part of any outcome will be anything to do with the intervention. Response, as well as outcome, depends on multiple factors including the patients' age, sex, aetiology and stage of heart failure, other cardiac, and non-cardiac comorbidities, success of the CRT implantation procedure and programming, and the quality of general management. Due to the fluctuating importance of these contributing factors, the relation between response to CRT and heart failure outcome is also heterogeneous. In addition, the suggested response markers show substantial disagreement [28].

Randomized controlled trials are the only reliable way of determining whether outcome and response to therapy 
are concordant or discordant. Observational studies, although superficially attractive, can only really assess outcome. Propensity-matched cohorts are a second-best solution compared with the randomized trial. Markers that have been suggested for selecting patients for CRT may identify patients with a better outcome but may do so by denying sick people who might have had a substantial response access to treatment and promoting implantation in patients with good outcomes but who had little or no response to treatment.

Heart failure tends to progress, and its characteristics will change over the course of the disease; QRS progressively increases, whilst symptoms deteriorate [19, 29]. Application of a rigid selection system leaves little opportunity for borderline cases [30]. By the time, the subject is eligible according to guidelines the optimal time for intervention may have been missed. So, for instance, a patient with LVSD who requires an ICD may not fulfil criteria for a CRT on the day of implant but may do so within 2-3 years. This patient should take the small additional risk of having a CRT-D device implanted, that may be programmed to deliver CRT or not, or run the risk of requiring a second procedure in a few years time [31]. Recently, data from large cohort studies in Western Europe and North America report significant "off-label" use of CRT [32-34] (Table 1). These off-label procedures may represent borderline cases where the experts made an intelligent choice to implant a device informed by trial evidence and the guidelines that they know are likely to change in the future.

Currently, the response to CRT cannot be reliably predicted due, in part, to incomplete understanding about how CRT works [35]. It seems certain that mechanical ventricular dyssynchrony is not the only target for CRT and, indeed, it may only be a minor factor for most patients [5, $36,37]$. Further developments in imaging technology may provide additional measurements-based on displacement imaging (Speckle Tracking) [38-41], viability and scar assessment [22, 23], exercise-induced left ventricular dyssynchrony and assessment for dynamic mitral regurgitation [42, 43] - that help improve current selection methodology. However, the whole exercise of trying to predict response may be futile and a flawed concept. Perhaps, the clinician with bed-side clinical skills and an ECG is best able to judge who should have CRT [17, 18, 44-51].

Rather than fretting about whether a patient who is indicated for a CRT will respond or not, more effort should be made to ensure that each patient has optimal management after the procedure [52-54]. However, the clinical value of trying to programme devices optimally is unclear and well-designed trials have been unable to show the benefit of individually tailored programming versus standard factory settings. It is possible that for most patients, the factory settings cannot be improved on but this does not preclude the possibility of benefit in some individuals that clinical trials, which investigate the average effect in a population or subpopulation, may not be able to detect. Device-integrated optimization methods provide alternatives to ones based on echocardiography, which are timeconsuming and require considerable expertise. However, recently published RCTs using intracardiac ECG-based optimization methods have failed to show a benefit for regular optimization compared with routine clinical practice (using fixed AV delay at $120 \mathrm{~ms}$ ) [55, 56]. In contrast, an implanted contractility sensor-based optimization method might improve the response to CRT [57]. The introduction of multipolar left ventricular leads will offer the possibility of choosing different left ventricular pacing sites or multisite pacing. For the moment, it appears that the conventional atrio- and interventricular delay settings are sufficient for most patients, but CRT optimization could be important for those with a suboptimal response to CRT.

Remote monitoring provides a new dimension to the management of heart failure. New technologies monitor not only device function but also patient physiology including heart rate and rhythm, heart rate variability, activity and thoracic bioimpedance that may help improve the management of heart failure [58-65]. Monitoring of the device function has already been shown to have benefits in terms of early warning of device failure. Whether and how physiological information can be used to improve patients' outcomes is the subject of intensive research.

Many other issues remain for future research. Patients with heart failure commonly have atrial fibrillation. If the

Table 1 Off-licence CRT implantation

\begin{tabular}{llllll}
\hline Database & Total number & LVEF $>35 \%$ & QRS $<120 \mathrm{~ms}$ & RBBB & NYHA I-II \\
\hline GWTG programme $^{\mathrm{a}}$ & $811^{\mathrm{e}}$ & $9.6 \%$ & $\mathrm{NA}$ & $\mathrm{NA}$ \\
European CRT survey $^{\mathrm{b}}$ & 2,438 & $17 \%$ & $9 \%$ & $6 \%$ & $2+20 \%$ \\
NCDR $^{\mathrm{c}}$ & 45,392 & $1.3 \%$ & $12 \%$ & NA & $13.1 \%$ \\
\hline
\end{tabular}

$N A$, not available; $L V E F$, left ventricular ejection fraction; $R B B B$, right bundle branch block; NYHA I-II, New York Heart Association class I-II

a American Heart Association's Get With The Guidelines-Heart Failure programme, ${ }^{\mathrm{b}}$ the European Cardiac Resynchronization Therapy Survey, ${ }^{c}$ the National Cardiovascular Data Registry Implantable Cardiac- Defibrillator Registry (US), ${ }^{\mathrm{d}}$ Before updating the guidelines in $2010,{ }^{\mathrm{e}}$ only new CRT implantation, overall study population included 33,898 heart failure patients 
main mechanism of benefit from CRT is delivered by atrioventricular resynchronization, this group of patients would not be expected to benefit from CRT. A recent metaanalysis of available evidence reported a similar improvement in ejection fraction but less symptomatic benefit for patients with atrial fibrillation compared with subjects in sinus rhythm after CRT [66]. The RAFT trial suggested that, compared to ICD, CRT-D did not reduce morbidity or mortality in patients with atrial fibrillation [16]. Bradyarrhythmias may be an important cause of sudden death in patients with heart failure [67], and this may be one of the reasons why CRT, even without a defibrillator function, can reduce the risk of sudden death $[68,69]$. Whether CRT-D is superior to CRT alone is uncertain. Better prediction of sudden death due to tachyarrhythmias might help target patients who need CRT-D rather than using it as a default option. CRT implantation technology is also improving that will enable better pacing site selection [70-72]. Implantation-related complications remain a problem [14, 73, 74] that future developments in lead technology and wireless electrodes may help overcome [75].

The present supplement offers a selection of review articles covering a broad range of subjects from bench to bedside in CRT. Topics have been selected either because there have been rapid advances or because there is a great deal of controversy and confusion surrounding them. Finally, we would like to express our sincere thanks to the dedicated authors who have contributed to this supplement and wish you enjoyable reading.

\section{References}

1. Cleland J, Daubert JC, Erdmann E et al (2005) The effect of cardiac resynchronization on morbidity and mortality in heart failure. N Engl J Med 352:1539-1549

2. Cleland JG, Daubert JC, Erdmann E et al (2006) Longer-term effects of cardiac resynchronization therapy on mortality in heart failure (the Cardiac Resynchroniztion-Heart Failure (CARE-HF) trial extension phase). Eur Heart J 27:1928-1932

3. Rivero-Ayerza M, Theuns DA, Garcia-Garcia HM et al (2006) Effects of cardiac resynchronization therapy on overall mortality and mode of death: a meta-analysis of randomized controlled trials. Eur Heart J 27:2682-2688

4. McAlister FA, Ezekowitz J, Hooton N et al (2007) Cardiac resynchronization therapy for patients with left ventricule systolic dysfunction: a systematic review. JAMA 297:2502-2514

5. Lendeers GE, Cramer MJ, Bogaard MD, et at (2010) Echocardiography prediction of outcome after cardiac resynchronization therapy: conventional methods and recent developments. Heart Fail Rev. doi: 10.1007/s10741-010-9200-8

6. Bilchick KC, Dimaano V, Wu KC et al (2008) Cardiac magnetic resonance assessment of dyssynchrony and myocardial scar predicts function class improvement following cardiac resynchronization therapy. JACC Cardiovasc Imaging 1:561-568

7. Gold MR, Niazi I, Giudici M et al (2007) A prospective comparison of $\mathrm{AV}$ delay programming methods for hemodynamic optimization during cardiac resynchronization therapy. J Cardiovasc Electrophysiol 18:1-7

8. Baker JH, MCKenzie J, Beau S et al (2007) Acute evaluation of programmer-guided AV/PV and VV delay optimization comparing an IEGM method and echocardiogram for cardiac resynchronization therapy in heart failure patients and dual-chamber ICD implants. J Cardiovasc Electrophysiol 18:185-191

9. Rickards AF, Bombardini T, Corbucci G et al (1996) An implantable intracardiac accelerometer for monitoring myocardial contractility. The Multicenter PEA Study Group. Pacing Clin Electrophysiol 19:2066-2071

10. Higgins SL, Hummel JD, Niazi IK et al (2003) Cardiac resynchronization therapy for the treatment of heart failure in patients with intraventricular conduction delay and malignant ventricular tachyarrhythmias. J Am Coll Cardiol 42:1454-1459

11. Cleland JGF, Freemantle N, Daubert J-C et al (2008) Long term effect of cardiac resynchronization in patients reporting mild symptoms of heart failure: a report from the CARE-heart failure Study. Heart 94:278-283

12. Abraham WT, Young JB, Leon AR et al (2004) Multicenter InSync ICD II Study Group. Effects of cardiac resynchronization in patients with left ventricular systolic dysfunction, an indication for an implantable cardioverter-defibrillator, and mildly symptomatic chronic heart failure. Circulation 110:2864-2868

13. Linde C, Abraham WT, Gold MR et al (2008) On behalf of the REVERSE (resynchronization reverses remodelling in systolic left ventricular dysfunction) Study Group. Randomized trial of cardiac resynchronization in mildly symptomatic heart failure patients and in asymptomatic patients with left ventricular dysfunction and previous heart failure symptoms. J Am Coll Cardiol 52:1834-1843

14. Daubert C, Gold MR, Abraham WT et al (2009) Prevention of disease progression by cardiac resynchronization therapy in patients with asymptomatic or mildly symptomatic left ventricular dysfunction. Insights from the European Cohort of the REVERSE (Resynchronization reverses remodelling in systolic left ventricular dysfunction) trial. J Am Coll Cardiol 54:1837-1847

15. Moss AJ, Hall WJ, Cannom DS et al (2009) For the MADIT-CRT trial investigators. Cardiac-resynchronization therapy for the prevention of heart-failure events. N Engl J Med 361(14):1329-1338

16. Tang ASL, Wells GA, Talajic M, et al (2010) Cardiac resynchronization therapy for mild-to-moderate heart failure. For the resynchronization-defibrillation for ambulatory heart failure trial (RAFT) investigators. N Engl J Med. doi:10.1056/NEJMoa 1009540

17. Jessup M, Abraham WT, Casey DE et al (2009) 2009 focused update incorporated into the ACC/AHA 2005 guidelines for the diagnosis and management of Heart Failure in Adults. JACC 53:e1-e90

18. Dickstein K, Vardas PE et al (2010) 2010 focused update of ESC guidelines on device therapy in heart failure. An update of the 2008 ESC guidelines for the diagnosis and treatment of acute and chronic heart failure and the 2007 ESC guidelines for cardiac resynchronization therapy. Eur Heart J 21:2677-2687

19. Marijon E, Trinquart L, Otmani A et al (2010) Predictors of short-term progressive heart failure death in New York Heart Association II patients implanted with a cardioverter defibrillatorthe EVADEF study. Am Heart J 159:659-664

20. Gasparini M, Regoli F, Galimberti P et al (2007) Three years of cardiac resynchronization therapy: could superior benefits be obtained in patients with heart failure and narrow QRS? Pacing Clin Electrophysiol 30(Suppl1):S34-S39

21. Achilli A, Peraldo C, Management Sassara et al (2006) Prediction of response to cardiac resynchronization therapy: the selection of candidates to CRT (SCART) Study. Pacing Clin Electrophysiol 29(Suppl2):S11-S19 
22. Iacopino S, Gasparini M, Zanon F et al (2010) Low-dose dobutamine stress echocardiography to assess left ventricular contractile reserve for cardiac resynchronization therapy: data from the Low-Dose Dobutamine Stress Echocardiography to Predict Cardiac Resynchronization Therapy Response (LODO-CRT) trial. Congest Heart Fail 16(3):104-110

23. Muto C, Gasparini M, Neja CP et al (2010) Presence of left ventricule contractile reserve predicts mid-term response to cardiac resynchronization therapy-results from the LODO-CRT trial. Heart Rhythm 11:1600-1605

24. Antonio N, Teixeira R, Coelho L et al (2009) Identification of "super-responders" to cardiac resynchronization therapy: the importance of symptom duration and left ventricular geometry. Europace 11:343-349

25. Rickard J, Kumbhani DJ, Popovic Z et al (2010) Characterization of super-response to cardiac resynchronization therapy. Heart Rhythm 7:885-889

26. Foley PW, Patel K, Irwin N et al (2011) Cardiac resynchronization therapy in patients with heart failure and a normal QRS duration: the RESPOND study. Heart 97(13):1041-1047

27. Cleland JGF, Tavazzi L, Daubert J-C et al (2009) Cardiac resynchronization therapy. Are modern myths preventing appropriate use? J Am Coll Cardiol 53:608-611

28. Fornwalt BK, Sprauge WW, BeDell P et al (2010) Agreement is poor among current criteria used to define response to cardiac resynchronization therapy. Circulation 121:1985-1991

29. Shamim W, Yousuffuddin M, Cicoria M et al (2002) Incremental changes in QRS duration in serial ECGs over time identify high risk elderly patients with heart failure. Heart 88:47-52

30. Cleland JGF, Tageldien A, Buga L et al (2010) Should we be trying to define responders to cardiac resynchronization therapy? JACC Cardiovasc Imaging 3:541-549

31. Cleland JGF, Tageldien A, Maarouf N, Hobson N (2008) Patients with heart failure who require an implantable defibrillator should have cardiac resynchronization routinely. Editor Heart 94:963-966

32. Dickstein K, Bogale N, Priori S, On behalf of the Scientific Committee National Coordinators et al (2009) The European cardiac resynchronization survey. Eur Heart J 30:2450-2460

33. Piccini JP, Hernandez AF, Dai D, For the Get With the Guidelines Steering Committee and Hospitals et al (2008) Use of cardiac resynchronization therapy in patients hospitalized with heart failure. Circulation 118:926-933

34. Fein AS, Wang Y, Curtis JP et al (2010) Prevalence and predictors of off-label use of cardiac resynchronization therapy in patients enrolled in the National Cardiovascular Data Registry Implantable Cardiac-Defibrillator Registry. J Am Coll Cardiol 56:766-773

35. Williams LK, Ellery S, Patel K et al (2009) Short-term hemodynamic effects of cardiac resynchronization therapy in patients with heart failure, a narrow QRS duration, and no dyssynchrony. Circulation 120:1687-1694

36. Hawkins NM, Petrie CM, Burgess MI, McMurray JJV (2009) Selecting patients for cardiac resynchronization therapy. J Am Coll Cardiol 53:1944-1959

37. Kass DA (2008) An epidemic of dyssynchrony. J Am Coll Cardiol 51:12-17

38. Gorcsan J 3rd, Tanabe M, Bleeker GB et al (2007) Combined longitudinal and radial dyssynchrony predicts response after cardiac resynchronization therapy. J Am Coll Cardiol 50:1476-1483

39. Bank AJ, Kaufman CL, Kelly AS et al (2009) Results of the prospective Minnesota study of ECHO/TDI cardiac resynchronization therapy (PROMISE-CRT) Study. J Card Fail 15:401-409

40. Tanaka H, Nesser HJ, Buck T et al (2010) Dyssynchrony by speckle-tracking echocardiography and response to cardiac resynchronization therapy: results of the speckle tracking and resynchronization (STAR) Study. Eur Heart J 31:1690-1700
41. Gorcsan J III, Oyenuga O, Habib PJ et al (2010) Relationship of echocardiographic dyssynchrony to long-term survival after cardiac resynchronization therapy. Circulation 122:1910-1918

42. Lancellotti P, Stainer PY, Lebois F et al (2005) Effect of dynamic left ventricule dyssynchrony on dynamic mitral regurgitation in patients with heart failure due to coronary artery disease. Am J Cardiol 96:1304-1307

43. Rocchi G, Bertini M, Biffi M et al (2009) Exercise stress echocardiography is superior to rest echocardiography in predicting left ventricule reverse remodelling and functional improvement after cardiac resynchronization therapy. Eur Heart J 30:89-97

44. Gottipaty VK, Krelis SP, Lu F et al (1999) The resting electrocardiogram provides a sensitive and inexpensive marker of prognosis inpatients with chronic congestive heart failure (abstract). JACC 33:145A

45. Kalra PR, Sharma R, Shamim W (2002) Clinical characteristics and survival of patients with chronic heart failure and prolonged QRS duration. Int J Cardiol 86(2-3):225-231

46. Molemma SA, Bleeker GB, van der Wall EE (2007) Usefulness of QRS duration to predict response to cardiac resynchronization therapy in patients with end-stage heart failure. Am J Cardiol $11: 1665-1670$

47. Kass DA (2003) Predicting cardiac resynchronization response by QRS duration. JACC 42:2125-2127

48. Cazeau SJ, Daubert JC, Tavazzi L et al (2008) Responders to cardiac resynchronization therapy with narrow or intermediate QRS complexes identified by simple echocardiographic indices of dyssynchrony: the DESIRE study. Eur J Heart Fail 10:273-280

49. Beshai JF, Grimm RA, Nagueh SF et al (2007) Cardiac-resynchronization therapy in heart failure with narrow QRS complexes. N Engl J Med 357:2461-2471

50. BommelRJ Van, Gorcsan J III, Chung ES (2010) Effects of cardiac resynchronization therapy in patients with heart failure having a narrow QRS complex enrolled in PROSPECT. Heart 96:1107-1113

51. Yu CM, Chan YS, Zhang Q et al (2006) Benefits of cardiac resynchronization therapy for heart failure patients with narrow QRS complexes and coexisting systolic asynchrony by echocardiography. JACC 48:2251-2257

52. Aranda JM, Woo GW, Schofeld RS et al (2005) Management of heart failure therapy after cardiac resynchronization therapy. Integrating advanced heart failure treatment with optimal device function. J Am Coll Cardiol 46:2193-2198

53. Mullens W, Grimm RA, Verga T et al (2009) Insights from a cardiac resynchronization optimization clinic as part of a heart failure disease management program. J Am Coll Cardiol 53:765-773

54. Fung JW, Chan JY, Kum LC et al (2007) Suboptimal medical therapy in patients with systolic heart failure is associated with less improvement by cardiac resynchronization therapy. Int $\mathbf{J}$ Cardiol 115:214-219

55. Abraham WT, Gras D, Yu CM et al (2010) Results from the FREEDOM trial-assess safety and efficacy of frequent optimization of cardiac resynchronization therapy. Heart Rhythm 7(5 suppl):2-3

56. Ellenbogen KA, Gold MR, Meyer TE, et al (2010) Primary results from the SmartDelay determined AV optimization: a comparison to other AV delay methods used in Cardiac Resynchronization Therapy (SMART-AV) trial. Circulation. doi: 10.1161/CIRCULATIONAHA.110.992552

57. Delnoy PP, Lunati M, Nagele $H$ et al (2010) Periodic VV and AV delays optimization in cardiac resynchronization therapy improves patients' clinical outcome: results from the CLEAR study. Herat Rhythm 7:S55 Abstract

58. Whellan DJ, Ousdigian KT, Al-Khatib SM et al (2010) Combined heart failure device diagnostics identify patients at higher risk of 
subsequent heart failure hospitalizations. Results from PARTNERS heart failure (Program to access and review trending information and evaluate Correlation to symptoms in patients with heart failure) Study. J Am Coll Cardiol 55:1803-1810

59. Singh JP, Rosenthal LS, Hranitzky PM et al (2009) Device diagnostics and long-term clinical outcome in patients receiving cardiac resynchronization therapy. Europace 11:1647-1653

60. Wang L (2007) Fundamentals of intrathoracic impedance monitoring in heart failure. Am J Cardiol 99(suppl):3G-10G

61. Raatikainen PMJ, Uusimaa P, van Ginneken MME et al (2008) Remote monitoring of implantable cardioverter defibrillator patients: a safe, time saving, and cost-effective means for follow up. Europace 10:1145-1151

62. Crossley GH, Chen J, Choucair W et al (2009) Clinical benefits of remote versus transtelefonic monitoring of implanted pacemakers. J Am Coll Cardiol 54:2012-2019

63. Caldwell JC, Contractor H, Petkar S et al (2009) Atrial fibrillation is under-recognized in chronic heart failure: insights form a heart failure cohort treated with cardiac resynchronization therapy. Europace 11(10): 1295-1300

64. Leclercq C, Padeletti L, Cihak R et al (2010) Incidence of paroxysmal atrial tachycardias in patients treated with CRT and continuously monitored by device diagnostics. Europace 12:71-77

65. Saxon LA, Hayes DL, Gilliam R et al (2010) Long-term outcome after ICD and CRT implantation and influence of remote device follow-up. The ALTITUDE Survival Study. Circulation 122:2359-2367

66. Upadhyay GA, Choudry NK, Auricchio A et al (2008) Cardiac resynchronization in patients with atrial fibrillation. A metaanalysis of prospective cohort studies. J Am Coll Cardiol 52:1239-1246

67. Thomsen PEB, Jons C, Patients Raatikainen et al (2010) Longterm recording of cardiac arrhythmias with an implantable cardiac monitor in patients with reduced ejection fraction after acute myocardial infarction. The cardiac arrhythmias and risk stratification after acute myocardial infarction (CARISMA) Study. Circulation 121:1258-1264

68. Cleland JGF, Buga L (2010) Device therapy: defibrillators-a shocking therapy for cardiomyopathy? Nat Rev Cardiol 2:69-70

69. Cleland JGF, Daubert JC, Erdman E et al (2006) Long term effects of cardiac resynchronization therapy on mortality in heart failure (the cardiac resynchronization-heart failure (CARE-HF) trial extension phase). Eur Heart J 16:1928-1932

70. Kassai I, Foldesi C, Szekely A, Szili-Torok T (2008) New method for cardiac resynchronization therapy: transapical endocardial lead implantation for left ventricular free wall pacing. Europace 10:882-883

71. Bogaard MD, Doevendans PA, Leenders GE et al (2010) Can optimization of pacing settings compensate for a non-optimal left ventricular pacing site? Europace 12:1262-1269

72. Delnoy PPHM, Ottervanger JP, Luttikhuis HO et al (2009) Pressure-volume loop analysis during implantation of biventricular pacemaker/cardiac resynchronization therapy device to optimize right and left ventricular pacing sites. Eur Heart $\mathbf{J}$ 30:797-804

73. Voigt A, Shalaby A (2010) Saba S. Continued rise in rates of cardiovascular implantable electronic device infections in the United States: temporal trends and causative insights PACE 33:414-419

74. Hauser RG, Katsiyiannis WT, Gornick CC et al (2010) Death and cardiovascular injuries due to device-assisted implantable cardioverter-defibrillator and pacemaker lead extraction. Europace 12:395-401

75. Lee KL, Tse HF, Lau CP et al (2007) First human demonstration of cardiac stimulation with transcutaneous ultrasound energy delivery: implications for wireless pacing with implantable devices. J Am Coll Cardiol 50(9):877-883 